\title{
ISOLATED HYPOPLASIA OF THE RIGHT VENTRICLE AND TRICUSPID VALVE IN SIBLINGS
}

\author{
BY
WILFRED E. MEDD, HENRY N. NEUFELD, WILLIAM H. WEIDMAN, AND JESSE E. EDWARDS

\author{
From the Mayo Clinic and Mayo Foundation (part of the Graduate School of the University of Minnesota), \\ Rochester, Minn., U.S.A.* \\ Received April 4, 1960
}

This paper describes the clinical and morbid anatomical findings in two siblings having hypoplasia of the right ventricle and tricuspid valve without other cardiac defects, and it discusses the possible hæmodynamic consequences and differential diagnosis of this malformation.

Hypoplasia of the right ventricular chamber is seen in tricuspid atresia (Taussig, 1947) and in some cases of pulmonary atresia with intact ventricular septum, and it may be associated with tricuspid hypoplasia in the latter condition (Chiche, 1952). Apparently however, there have been no previous descriptions of isolated hypoplasia of the right ventricle and tricuspid valve, although Keith et al. (1958) list this combination as one that can be mistaken for tricuspid atresia. It is convenient to distinguish pathologically congenital tricuspid stenosis, in which the orifice is narrow because of failure of commissural separation, from tricuspid hypoplasia, in which the orifice is reduced by the small size of the valvular ring but the small valvular leaflets are otherwise essentially normal. In our cases the right ventricular hypoplasia consisted in abnormally small external size, wall thickness, and chamber capacity.

\section{REPORT OF CASES}

Clinical Observations. Case 1.-The patient, a girl, was born in August, 1954. Her mother had had one previous pregnancy, resulting in a child then living but with hemophilia. The parents did not know of any congenital malformations in their families, and there was no history of consanguinity.

Examination on the day of birth showed cyanosis, which was improved by administration of oxygen and worsened with crying. The heart rate was regular at 120 a minute. No murmurs were heard. The liver was palpable $3 \mathrm{~cm}$. below the costal margin and was pulsating. The femoral pulses and the remainder of the clinical findings were normal.

The thoracic rœntgenogram (Fig. 1a) showed a long transverse cardiac diameter with prominence of the right cardiac border, suggesting right atrial enlargement, and abnormally pale pulmonary vascular markings. The cardiogram (Fig. 1b) was interpreted as showing right atrial enlargement, prolonged atrioventricular conduction, and poor function of the right ventricle.

The diagnosis was right-to-left interatrial shunt with poor function of the right ventricle, possibly associated with tricuspid or pulmonary atresia. The next day the child was less lively and more cyanosed; and exploratory thoracotomy was done with a view to increasing the pulmonary blood flow, even if no corrective surgery was possible. At operation probes were passed through the tricuspid and pulmonary orifices via a small right ventriculotomy, thus excluding tricuspid or pulmonary atresia. Following these manipulations the child's condition gradually failed and she died.

The significant abnormalities found at necropsy were confined to the heart and will be described later with those in Case 2.

* This work was supported in part by Research Grant No. H-4014 from the National Heart Institute, U.S. Public Health Service. It was carried out while W.E.M. was at the Mayo Clinic in receipt of a grant from the Endowment Fund, St Thomas' Hospital, London. 
Case 2. The mother of Case 1 had a third pregnancy, with a normal infant born in 1956. A fourth pregnancy, also uneventful, resulted in birth of a boy, this case, in September, 1959. Cyanosis was noticed from birth. On examination the baby was vigorous and weighed $3.1 \mathrm{~kg}$., but had cyanosis, equal in the upper and lower halves of the body, which increased with crying. The heart rate was regular at 120 a minute. No cardiac overactivity was detected. The first and second sounds were normal in intensity and were not split.

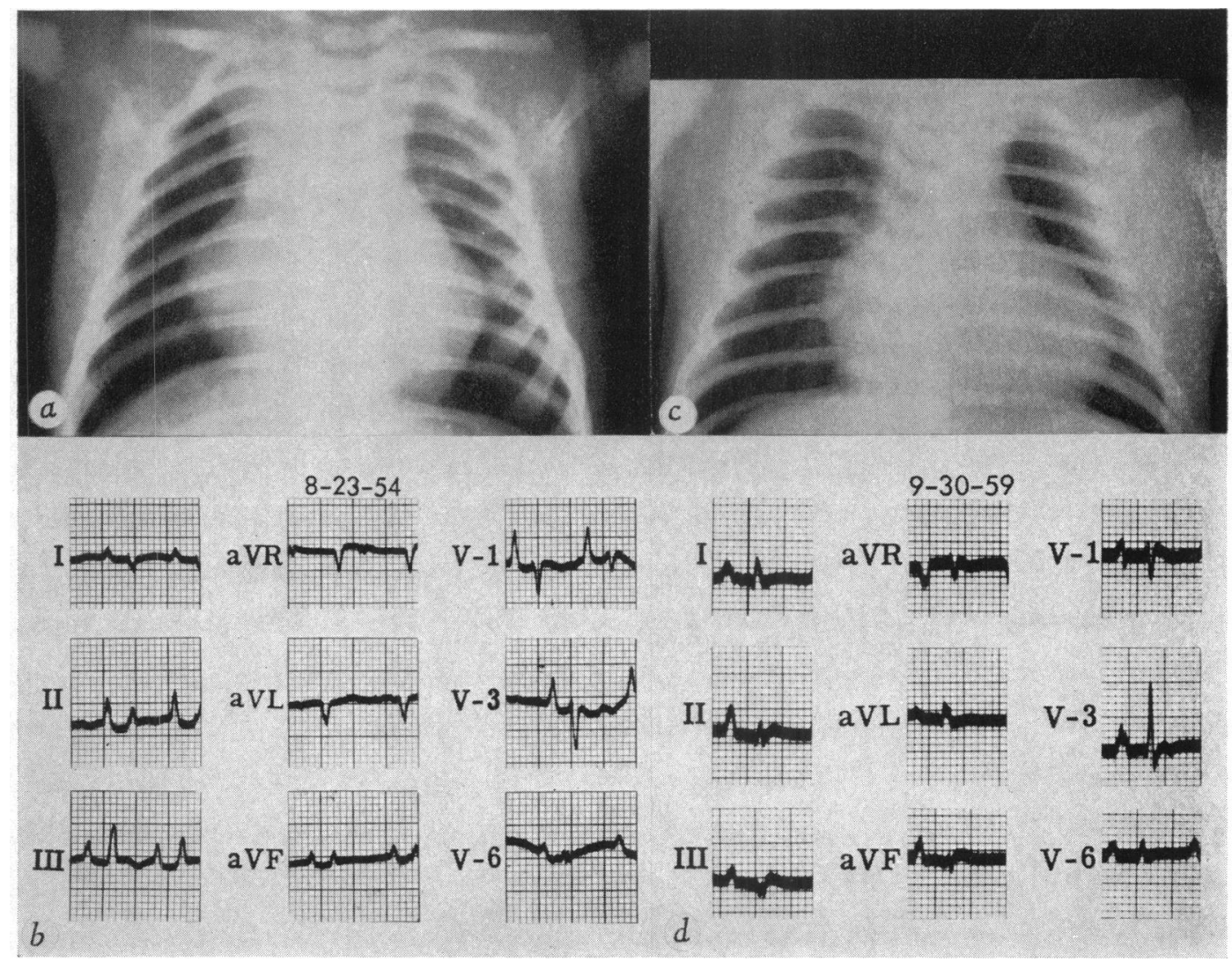

FIG. 1.-(a) Thoracic roentgenogram showing cardiothoracic ratio of 62 per cent, prominence of the right border compatible with right atrial enlargement, and pale pulmonary vascular markings. Case 1.

(b) Mean QRS axis $+110^{\circ}$. Vectorial analysis of this scalar electrocardiogram in the frontal plane showed a clockwise loop. Tall $P$ waves. $P-R$ interval 0.16 sec. $r S$ pattern in V1. Splintered lowvoltage QRS complex in V6. T waves flat or negative. Case 1 .

(c) Thoracic roentgenogram showing cardiothoracic ratio of 60 per cent, prominence of the right border compatible with right atrial enlargement, and pale pulmonary vascular markings. Case 2.

(d) Mean QRS axis in frontal plane $-10^{\circ}$. Vectorial analysis in the frontal plane showed a counterclockwise loop. P waves tall in lead II, notched in lead I. P-R interval $0 \cdot 18 \mathrm{sec}$. rS pattern in lead V1. qRs pattern in lead V6. T waves flattened. Case 2.

An added sound was heard in late diastole but there were no murmurs. The lungs were clear on auscultation. The liver was palpable $2 \mathrm{~cm}$. below the costal margin and was pulsating. The femoral pulses and the findings from the remainder of the physical examination were normal.

The thoracic rœntgenogram (Fig. 1c) showed a transverse cardiac diameter slightly longer than normal, prominence of the right border compatible with right atrial enlargement, and paleness of the pulmonary vascular markings. The cardiogram (Fig. 1d) suggested right-and possibly also left-atrial hypertrophy without evidence of a normally functioning right ventricle. 
Because the clinical findings in this case were similar to those in Case 1, and because siblings tend to have the same type of congenital heart disease, it seemed likely that he had the same malformation. Full doses of digitalis brought no improvement, and the child died six days after birth.

At necropsy only the heart showed significant abnormalities. The specimen will be described now, with that from Case 1.

Pathological Observations. The hearts in the two cases (Fig. 2, 3, and 4) were essentially similar, and they can be described together. The great vessels were normally interrelated and the venous connections of the heart were normal. Low in the ventricular portion of the heart was a concavity corresponding to the normal location of the inflow part of the right ventricle. The right atrium was dilated and its wall hypertrophied.

The interior of the heart revealed that the atrial septum was normal; but in each case the foramen ovale was patent, though valvular-competent. The tricuspid orifice was guarded by a tricuspid valve which was normal in respect to form, but the valve itself and the orifice were diminutive. In each instance the orifice measured only about $6 \mathrm{~mm}$. in diameter. The tricuspid valve led into the right ventricle, which appeared hypoplastic. The elements of the outflow portion could be identified readily. The apical or inflow portion of the ventricle, however, was mostly lacking, so the right ventricular chamber was considerably smaller than normal.

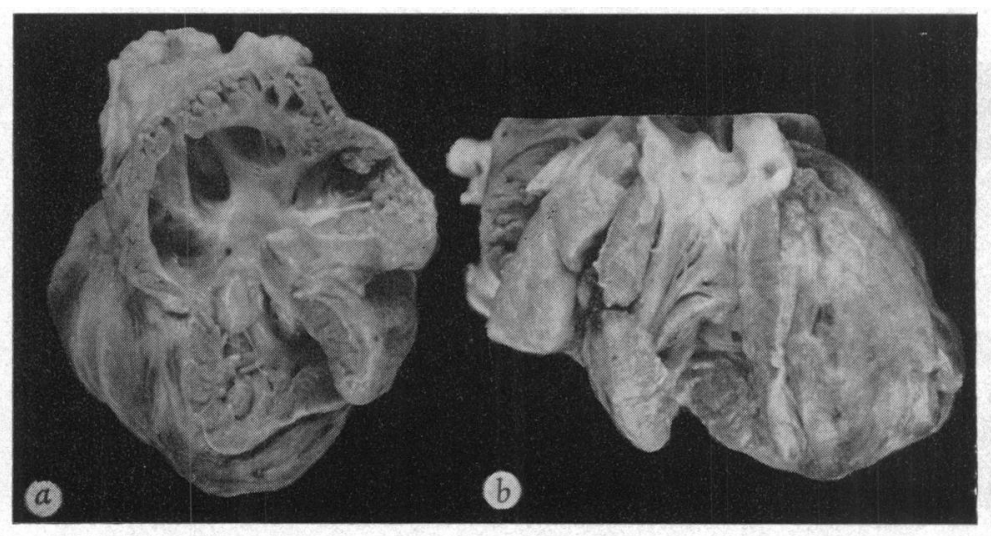

FIG. 2

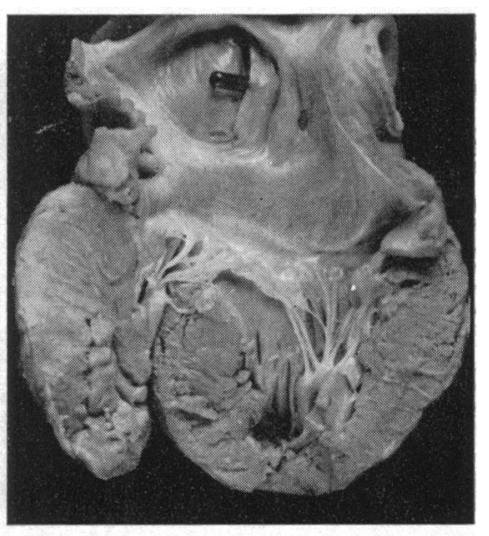

FIG. 3.

FIG. 2, Case 1.-(a) Right side of heart. The right atrial chamber is enlarged and its wall is hypertrophied. The form of the tricuspid valve is intrinsically normal, but the orifice is narrow. Only a small part of the inflow portion of the right ventricle is formed.

(b) Right ventricle and pulmonary valve. Major portion of the small right ventricle is composed of outflow tract. Its wall is relatively thick but normal for this age. Major part of ventricular mass of heart is formed by left ventricle.

FIG. 3, Case 1.-Left side of heart. Probe in patent foramen ovale. Mitral valve and left-sided chambers are normal.

The pulmonary orifice was normal in size and was guarded by three cusps, and the pulmonary tract was of normal calibre. The mitral and aortic valves and the left ventricle were normal. The ductus arteriosus was patent in both cases, but appeared in each to be unusually narrow for a newborn infant.

Histological examination of the small branches of the pulmonary arteries by Dr. C. A. Wagenvoort using his own technique (Wagenvoort, in press), showed that, as compared with data from controls of the same age, both the thickness of the media and the area of medial surface per unit of lung tissue were within the range of normal in Case 1 and were much bəlow normal in Case 2 . The significance of this finding is as yet uncertain. 


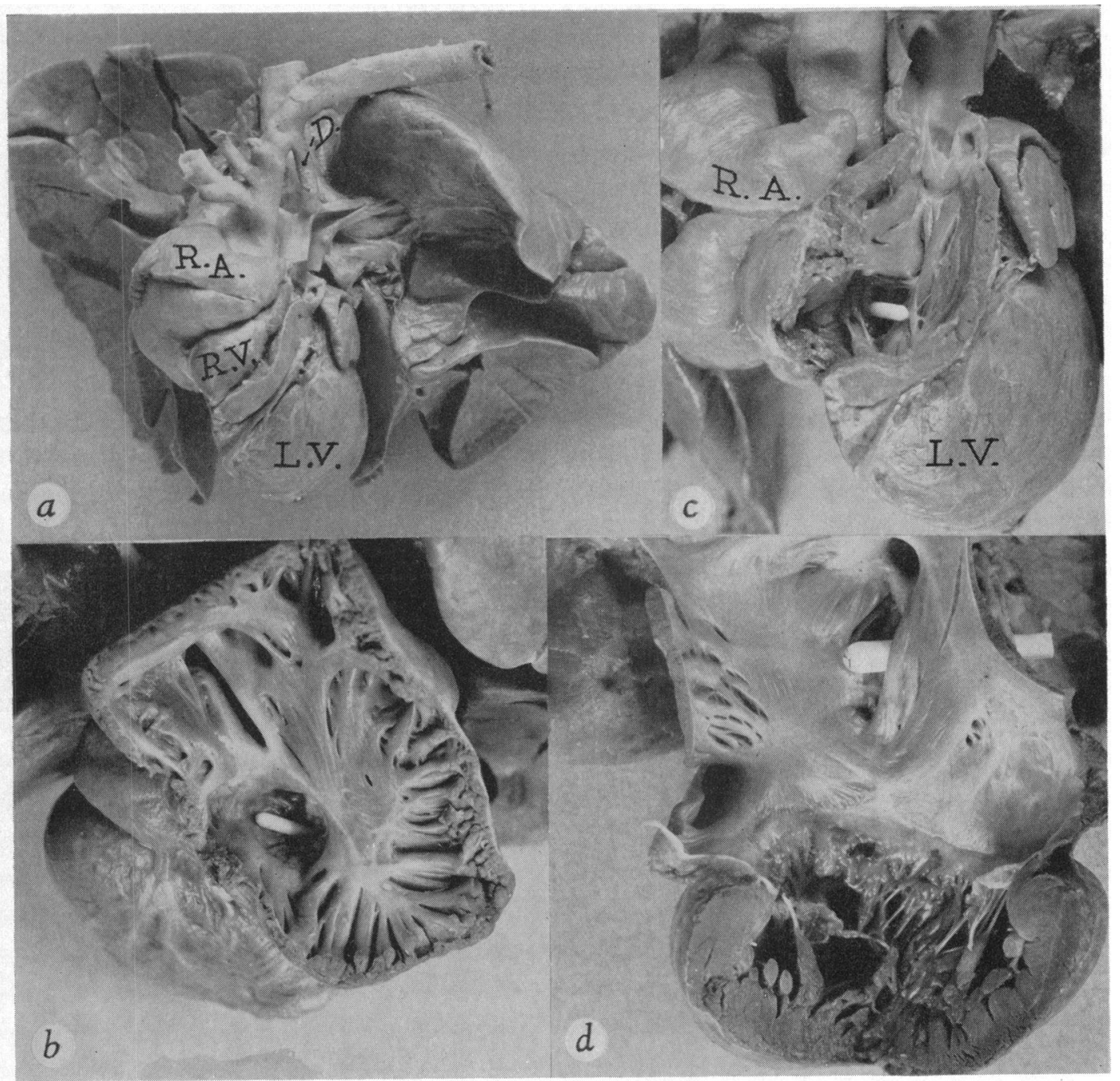

FIG. 4, Case 2.-(a) Exterior of heart and lungs. The right atrium (R.A.) is grossly dilated and its wall is hypertrophied. The right ventricle (R.V.) is hypoplastic. L.V.=left ventricle. A narrow patent ductus arteriosus (D) is present.

(b) Right atrium. Probe lies in the hypoplastic but otherwise normal tricuspid valve. Right atrial wall is hypertrophied and chamber is dilated.

(c) Right ventricle and pulmonary valve. Probe lies in the hypoplastic tricuspid valve. The right ventricular chamber is hypoplastic, being composed of hardly more than the outflow portion. The left ventricle (L.V.) forms the major part of the ventricular mass of heart.

$(d)$ Left side of heart. Probe is in patent foramen ovale. The mitral valve and left-side chambers are normal.

\section{Discussion}

Although there are occasional reports of congenital tricuspid stenosis, usually with associated cardiac defects (Peacock, 1854; Vierordt, 1901; Abbott, 1936; Kjellberg et al., 1955; and others), a search has not revealed any case similar to the pair reported here. Similar hypoplasia of the right ventricle and tricuspid valve has, however, been described with other abnormalities, for instance, pulmonary atresia (Chiche, 1952; Keith et al., 1958), infundibular pulmonary stenosis and ventricular 
septal defect (Chiche, 1952), and pulmonary valvular stenosis, ventricular septal defect, and transposition of the great vessels (Durand and Metianu, 1954).

Two cases of isolated right ventricular hypoplasia with normal tricuspid valves were mentioned by Cooley et al. (1950). Gasul et al. (1959) reported a case in which the differentiation between Ebstein's disease and hypoplasia of the right ventricle remained undecided despite thorough investigation and thoracotomy: there was no evidence of tricuspid stenosis.

Hamodynamics. Since cardiac catheterization was not done in either of the cases here reported, the hæmodynamics can only be conjectured from the clinical and pathological findings. These two infants had cyanosis as an effect of right-to-left shunting through the patent foramen ovale, but it is not certain what was the fundamental cause of the obstruction to blood flow that raised the right atrial pressure above the left. It seems likely, however, that both the smallness of the tricuspid orifice and the smallness of the right ventricular cavity would tend to raise the right atrial pressure, the former by producing an early diastolic gradient across the valve and the latter by raising the end-diastolic ventricular pressure. At cardiac catheterization in a future case it might be possible to assess these two factors. An additional load on the small right ventricle in early life would be the normal elevation of pulmonary vascular resistance at that age (Edwards, 1960).

Cause of the Ventricular Hypoplasia. Whether the hypoplasia of the right ventricle in these cases is a primary developmental abnormality or whether it is due to a reduction of tricuspid flow in fœtal life is open to question. That selective failure of development of a ventricle can occur is illustrated by two cases of right ventricular hypoplasia with normal tricuspid valves (Cooley et al., 1950) and the case of a 7-month-old child described by Uhl (1952), in whom the myocardium was absent from an otherwise normal right ventricle. Similar indirect evidence in favour of primary ventricular hypoplasia in our cases is provided by the work of Fales (1946), who found experimentally that the hearts of salamanders (Ambystoma punctatum) often developed to normal external size without blood flow through them, although the ventricular cavity tended to be reduced.

Differential Diagnosis. The malformation here described will have to be distinguished from other conditions that may cause cyanosis from birth with clinical, rœntgenographic, and electrocardiographic evidence of right atrial hypertrophy and rœntgenographic evidence of reduction in pulmonary blood flow without clinical or cardiographic evidence of right ventricular hypertrophy. The principal anomalies in this group are tricuspid atresia, Ebstein's malformation, pulmonary atresia with intact ventricular septum, and congenital tricuspid stenosis.

Tricuspid Atresia. The clinical appearance in our cases was similar to that in tricuspid atresia except that Case 1 had a mean QRS axis of +110 : an axis so far to the right rarely occurs in tricuspid atresia. Evidence against tricuspid atresia would be afforded if the first heart sound were split or if a pathway from right atrium to right ventricle could be demonstrated by passing a catheter through the valve, by angiography, or by an indicator-dilution technic (Birkhead and Wood, 1957).

Ebstein's Malformation. The cardiogram is likely to help in differentiating Ebstein's malformation, since, it usually shows complete or incomplete right bundle-branch block (although the $\mathbf{R}$ wave in lead V1 may not be so tall as is usual in these types of block). This sign may not be so reliable in infants, however, since the QRS duration may become abnormal only later in life (Blount et al., 1957). Cases of Ebstein's malformation with Wolff-Parkinson-White syndrome type B (Sodi-Pallares, 1956; Schiebler et al., 1959) resemble the two reported here in the absence of tall $\mathrm{R}$ waves in lead V1, but can be distinguished by their wide QRS complex and short P-R interval. In those few patients having Ebstein's malformation with a normal QRS duration and an rS pattern in lead V1 (Broadbent et al., 1953; Schiebler et al., 1959) more direct evidence for the anomaly may be obtained by finding leftward and upward displacement of the tricuspid orifice at catheterization. Minor anatomical valvular displacement of the Ebstein type, however, might be indistinguishable from the normal situation and yet be responsible for tricuspid insufficiency and a right-to-left interatrial shunt.

Pulmonary Atresia with Intact Ventricular Septum. If the right ventricle is small, the cardiogram may resemble those in our cases. The diagnosis of pulmonary atresia depends on angiographic demonstration of complete obstruction to the right ventricular infundibulum. Splitting of the second heart sound excludes pulmonary atresia.

Congenital Tricuspid Stenosis. The possibility of treating patients with congenital tricuspid stenosis by 
commissural splitting and closure of the interatrial communication, as has been performed in one case (Medd and Kinmonth, unpublished data), makes it desirable to distinguish that anomaly from hypoplasia of the right ventricle and tricuspid valve. Without adequate hæmodynamic data in the two entities, however, it is not possible to postulate a diagnostic method-especially since an interatrial communication reduces the diastolic gradient across the valve.

Familial Tendency. The occurrence of the present rare malformation in siblings lends support to the conclusion of Campbell (1959) that if two cases of congenital heart disease occur in one family the tendency of the anomaly to be similar in type is greater than can be attributed to chance. His material included a series of 26 families in which sibs were affected: in all 14 of the pairs in which neither sib was cyanosed, the type of heart disease was certainly or probably the same, and among the 12 pairs in which one or both were cyanosed there was a tendency toward similarity, though less clear-cut.

Treatment. Anastomosis of the superior vena cava and the right main pulmonary artery was suggested by Glen (1958) to counteract various malformations of the right side of the heart, some of which have a functional effect similar to that in the present cases. This procedure is not yet evaluated and the authors have no personal experience of it. It was performed in the case of Ebstein's malformation or right ventricular hypoplasia reported by Gasul et al. (1959).

\section{SUMMARY}

In two sibling infants, isolated hypoplasia of the right ventricle and tricuspid valve (an anomaly not described elsewhere) gave the clinical appearance of a right-to-left interatrial shunt with evidence of diminished right ventricular function. Other malformations that may produce this picture are tricuspid atresia, pulmonary atresia with an intact ventricular septum and a small right ventricular chamber, Ebstein's malformation, and congenital tricuspid stenosis. Correct differential diagnosis is important because of the possibility of definitive surgery in some cases of pulmonary atresia and congenital tricuspid stenosis. Electrocardiography and angiocardiography appear to be the principal methods for achieving such diagnosis.

\section{REFERENCES}

Abbott, M. E. (1936). Atlas of Congenital Heart Disease. New York, American Heart Association, 1936, p. 44. Birkhead, N. C., and Wood, E. H. (1957). Proc Mayo Clin., 32, 506.

Blount, S. G., Jr., McCord, M. C., and Gelb, I. J. (1957). Circulation, 15, 210.

Broadbent, J. C., Wood, E..H., Burchell, H. B., and Parker, R. L. (1953). Proc. Mayo Clin., $28,79$.

Campbell, M. (1959) Brit. Heart J., 21, 65.

Chiche, P. (1952). Arch. Mal. Coeur, 45, 980.

Cooley, R. M., Sloan, R. D., Hanlon, C. R., and Bahnson, H. T. (1950). Radiology, 54, 848.

Durand, M., and Metianu, C. (1954). In Donzelot, E, and D'Allaines, F., Traité des Cardiopathies congénitales. Paris, Masson et Cie, 1954, pp. 1-11.

Edwards, J. E. (1960). Congenital Malformations of the Heart and Great Vessels. In Gould, S. E., Pathology of the Heart. 2nd ed. Springfield, Ill., Charles C. Thomas, pp. 260-293.

Fales, Doris E. (1946). J. Exper. Zool., 101, 281.

Gasul, B. M., Weinberg, M., Luan, L. L., Fell, E. H., Bicoff, J., and Steiger, Z. (1959). J. Amer. med. Ass., $171,1797$.

Glenn, W. W. L. (1958). New England J. Med., 259, 117.

Keith, J. D., Rowe, R. D., and Vlad, P. (1958). Heart Disease in Infancy and Childhood. New York, Macmillan Company, pp. 434 and 570.

Kjellberg, S. R., Mannheimer, E., Rudhe, U., and Jonsson, B. (1955). Diagnosis of Congenital Heart Disease. Chicago, Year Book Publishers, Inc., p. 561.

Medd, W. E., and Kinmonth, J. B. Unpublished data.

Peacock, T. B. (1854). Trans. Path. Soc. London, 5, 64.

Schiebler, G. L., Adams, P., Jr., Anderson, R. C., Amplatz, K., and Lester, R. G. (1959). Circulation, $19,165$.

Sodi-Pallares, D. (1956). New Bases of Electrocardiography. (English translation by R. M. Calder, editor.) St. Louis, The C. V. Mosby Company, p. 572.

Taussig, Helen B. (1947). Congenital Malformations of the Heart. New York, Commonwealth Fund, 618 pp.

Uhl, H. S. M. (1952). Bull. Johns Hopk. Hosp., 91, 197.

Vierordt, H. (1901). In Nothnagel's Specielle Pathologie und Therapie. Wien, H, vol. 15 (2). p. 200

Wagenvoort, C. A. Circulation, Vasoconstriction and medial hypertrophy in pulmonary hypertension, In press. 